\title{
The sweet disease
}

Cite as: CMAJ 2018 October 22;190:E1261. doi: 10.1503/cmaj.180763

His lips on mine like algal blooms on stagnant water spread me.

Our legs entwined as milfoil, bound as we once were to the stop \& go \& go \& go until we thought we were gone.

Immune to thoughts of disease, the rush of lust's sweetness fuelled me.

I rose to his touch like the Sagrada Familia ever-expanding, unfinished cathedral my skin translucent as leaded panes, the holy, holy, whole

I imagined embraceable. My immunity is now fractured; highs and lows of sugar siphon spontaneity.

Ebbing, my mind reels in undertow and worry: will I die

in a car crash, will I injure others

with words spouted

at random, will anyone stay with me as I surf this wave, forever? In endless routines I claim my body's rites: daily test strips, calculated eating, and stake out its beauty.

Stained and glassed my tattooed cells radiate a full house of hues.

Replicating their miscoded chain

in a roar of rearranged notes, they attack.

Some days I am shaky, beached, untouchable. Other times I'm cresting as I come ashore, as if the islets of Langerhans birthplace of insulin - were Hawaiian, full

of birdsong and their saving ichor, which I must now inject into this gyrating score, this chemistry humming with flagrancy.

\section{Suzanne Edison MA MFA}

\section{Seattle, Wash.}

This article has not been peer reviewed.

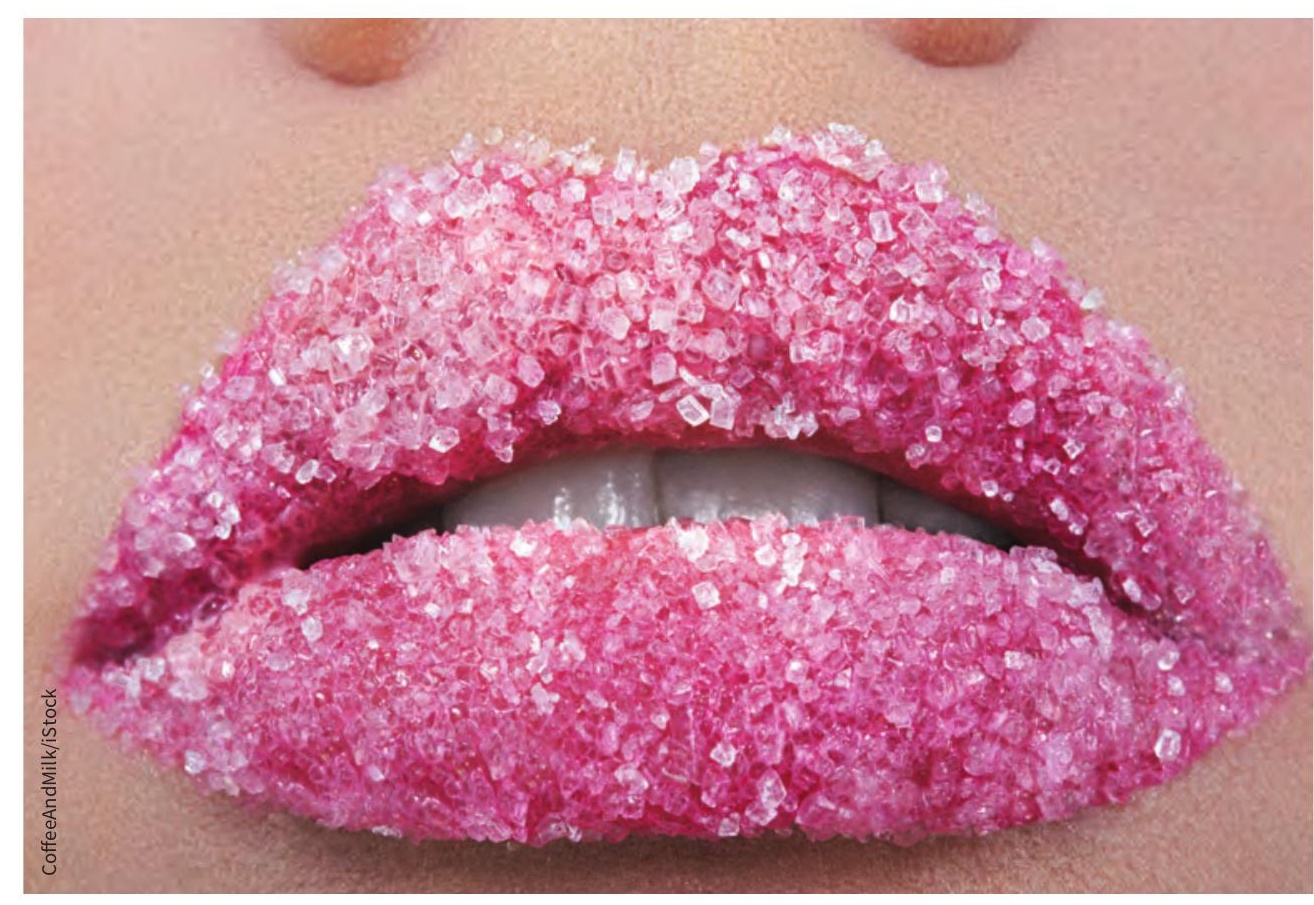

